\title{
Delay of emergency surgical interventions in Ethiopia: Patient and health system factors
}

\author{
Girmaye Tamrat' ${ }^{1}$, Mensur Osman², Nigussie Deyessa ${ }^{3}$, Mulat Taye' ${ }^{1}$, Ronald Lett $^{4}$, Abebe Bekele ${ }^{1}$ \\ 1. Department of Surgery, School of Medicine, Addis Ababa University, Addis Ababa, Ethiopia \\ 2. College of Medicine and Health Science, University of Gondar, Gondar, Ethiopia \\ 3. School of Public Health, Addis Ababa University, Addis Ababa, Ethiopia \\ 4. Canadian Network for International Surgery, Vancouver, British Columbia, Canada
}

Correspondence: Dr Girmaye Tamrat (girmayet@yahoo.com)

(C) 2018 G. Tamrat et al. This open access article is licensed under a Creative Commons Attribution 4.0 International License (http://creativecommons.org/licenses/by/4.0/) which permits unrestricted use, distribution, and reproduction in any medium, provided you give appropriate credit to the original author(s) and the source, provide a link to the Creative Commons license, and indicate if changes were made.

East Cent Afr J Surg. 2018 Aug;23(2):59-65 https://dx.doi.org/10.4314/ecajs.v23i2.2

\begin{abstract}
\section{Background}

The objectives of this study were to evaluate outcomes among patients with acute abdomen and abdominal trauma who presented at either of 2 referral hospitals in Addis Ababa, Ethiopia, and to determine the factors associated with delay as well as the effects of prehospital and in-hospital delay on outcome.

Methods

We conducted a 1-year prospective cross-sectional study, which included all cases of surgically treated acute abdomen and abdominal trauma admitted to St Paul General Specialized Hospital, Addis Ababa, Ethiopia and Gondar University Hospital, Gondar, Ethiopia. Standardized data collection forms were completed for all cases from 1 May 2008 to 30 April 2009. Data were analyzed using Epi Info version 6 and SPSS version 13
\end{abstract}

\begin{abstract}
Results
A total of 504 patients were studied. Diagnoses were: intestinal obstruction (34.6\%), appendicitis (33\%), and perforated peptic ulcer (3.6\%). Sixty-six percent of patients over 45 years of age, $60 \%$ of females, and $61 \%$ of intestinal obstruction cases were operated on within 3 days of illness onset. The $35 \%$ of patients who were operated on more than 3 days after the development of symptoms had a mortality of $67 \%$. Fifty-four percent of the cases with a total prehospital and in-hospital time of more than 3 days had initially visited other health institutions.
\end{abstract}

\section{Conclusions}

Delay of surgical intervention of more than 3 days for acute abdomen or abdominal trauma adversely affected outcomes. Women, patients older than 45 years of age, patients with intestinal obstruction, and those who were referred from other health facilities were delayed and had adverse outcomes.

Keywords: delay in surgery, acute abdomen, abdominal trauma, surgical systems improvement

\section{Introduction}

Delayed treatment of surgical emergencies is associated with increased morbidity and mortality. For acute abdomen, intervention must be timely but individualized. Studies have shown that there is a male predominance in the most common causes of acute abdomen..$^{1-4}$ Some abdominal surgical emergencies are optimally managed within minutes, others within hours, while other conditions require observation and surgical intervention may end up being unnecessary or be safely deferred for several days. ${ }^{4}$
A study conducted at a district hospital in the United Kingdom showed that after admission there were unacceptable delays in the surgical management of $14 \%$ of 260 patients undergoing emergency surgery. ${ }^{5}$ The consequences of delayed surgical intervention include added patient discomfort, anxiety and inconvenience, and serious complications including death. Early operative control of haemorrhage is vital, and delays in laparotomy of over 2 hours for intra-abdominal bleeding adversely affects outcomes. ${ }^{6}$

A Pennsylvania trauma registry study of 243 patients with intra-abdominal bleeding and hypotension demon- 
strated a $1 \%$ increase in risk of death for every 3 minutes spent in the emergency department before surgery. ${ }^{7}$

In both Asia and America, pre-admission delays for appendicitis cases have been associated with increased perforation rates, systemic complication rates, and extended duration of hospital stay. Delays of 72 hours or more are associated with serious complications among appendcitis cases. ${ }^{8,9}$ A hospital study in southern Ethiopia found a mortality rate of $13.5 \%$ for acute abdomen; mortality was mainly attributed to delayed presentation, diagnosis, and treatment. ${ }^{10}$

\begin{tabular}{ccccc}
\hline \multicolumn{4}{l}{ Table 1. Sociodemographic characteristics of study subjects } & \\
\hline Characteristics & Frequency & Percent & $\begin{array}{c}\text { Reference } \\
\text { Parameter* }\end{array}$ & P value \\
\hline \hline Age group (years; $\mathbf{n}=\mathbf{5 0 4})$ & & & & \\
$<25$ & 201 & 40.0 & 2824 aa & $<0.01$ \\
$25-44$ & 194 & 38.5 & 3630 & \\
$\geq 45$ & 109 & 21.4 & 2242 & \\
\hline
\end{tabular}

\begin{tabular}{|c|c|c|c|c|}
\hline \multicolumn{5}{|l|}{$\operatorname{Sex}(n=504)$} \\
\hline Male & 367 & 72.8 & $6,823 \mathrm{cc}$ & \multirow{2}{*}{$<0.01$} \\
\hline Female & 137 & 27.2 & 8,880 & \\
\hline \multicolumn{5}{|c|}{ Marital status ( $n=489$ ) } \\
\hline Single & 238 & 48.7 & 2417 aа & \multirow{3}{*}{$<0.01$} \\
\hline Married & 230 & 47.0 & 2890 & \\
\hline $\begin{array}{l}\text { Divorced/ } \\
\text { widowed }\end{array}$ & 21 & 4.3 & 157 & \\
\hline \multicolumn{5}{|l|}{ Religion ( $n=499$ ) } \\
\hline Orthodox & 406 & 81.4 & $93514 c c$ & \multirow{3}{*}{$<0.01$} \\
\hline Muslim & 79 & 15.8 & 17770 & \\
\hline Other & 14 & 2.8 & 448 & \\
\hline \multicolumn{5}{|l|}{ Education ( $n=495$ ) } \\
\hline None & 75 & 15.2 & 2164 aа & \multirow{3}{*}{$<0.01$} \\
\hline Elementary & 150 & 30.3 & 2140 & \\
\hline $\begin{array}{r}\text { Secondary or } \\
\text { more }\end{array}$ & 270 & 54.5 & 1160 & \\
\hline \multicolumn{5}{|c|}{ Monthly income $(n=267)$} \\
\hline$<1800$ Birr & 126 & 47.2 & 15292 cc & \multirow{3}{*}{$>0.05$} \\
\hline 1800-5999 Birr & 107 & 40.1 & 15179 & \\
\hline$\geq 6000$ Birr & 34 & 12.7 & 6531 & \\
\hline \multicolumn{5}{|c|}{ Referral System $(n=391)$} \\
\hline Self & 125 & 32.0 & & \\
\hline $\begin{array}{l}\text { Healthcare } \\
\text { institution }\end{array}$ & 266 & 68.0 & & \\
\hline \multicolumn{5}{|l|}{ Site } \\
\hline Addis Ababa & 341 & 69.0 & & \\
\hline Gondar & 153 & 31.0 & & \\
\hline
\end{tabular}


Table 2. Magnitude of mortality, complication and distribution of prehospital/hospital time of study subjects

\begin{tabular}{lccc}
\hline \multicolumn{1}{c}{ Characteristics } & $\begin{array}{c}\text { Number of cases } \\
\text { studied }\end{array}$ & Percent & $(\mathbf{9 5 \%} \mathbf{C l})$ \\
\hline \hline $\begin{array}{l}\text { Complication upon } \\
\text { arrival }\end{array}$ & 462 & 35.3 & $(30.9,39.7)$ \\
$\begin{array}{l}\text { Post-operative } \\
\text { complications }\end{array}$ & 424 & 19.6 & $(15.8,14.1)$ \\
Death & 382 & 11.0 & $(7.9,14.1)$ \\
\hline
\end{tabular}

\begin{tabular}{|c|c|c|}
\hline Characteristics & Frequency & Percent \\
\hline \multicolumn{3}{|c|}{ Pre-hospital Time $(n=324)$} \\
\hline$<1$ day & 139 & 42.9 \\
\hline 2-3 days & 73 & 22.5 \\
\hline$>3$ days & 112 & 34.6 \\
\hline \multicolumn{3}{|c|}{$\begin{array}{l}\text { Hospital Time (Outpatient+ Inpatient Time) } \\
(n=393)\end{array}$} \\
\hline $0-3 \mathrm{hrs}$ & 291 & 74.0 \\
\hline$>3 \mathrm{hrs}$ & 102 & 26.0 \\
\hline
\end{tabular}

A study in northwestern Ethiopia found a mortality of $20 \%$ among 25 cases of small bowel volvulus; all deaths were operated on more than 3 days after the onset of the illness. ${ }^{11}$ In Addis Ababa, 73 patients with perforated peptic ulcers had a case fatality proportion of $18.9 \%$; the high mortality was attributed to delays in presentation, purulent peritonitis, sepsis, prolonged preoperative preparation, and insufficient therapeutic facilities. ${ }^{12}$

Accessibility and availability are crucial concepts in low-resource settings and can be investigated under the lens of the "Three Delays" (delays in seeking care, reaching care, and receiving care) conceptualization to explain the delay between symptom onset and receipt of appropriate care. ${ }^{13}$

In Ethiopia, there has been inadequate evaluation of the magnitude of the surgical delay issue, the reasons for surgical delays, and the extents to which patient factors and health system factors contribute to delays. The objectives of this study were to evaluate the effect of time on patient outcomes, assess patient and the healthcare system contributors of delays at 2 referral hospitals, and to determine prehospital and in-hospital causes of delayed management of abdominal surgical emergencies. By identifying the main factors responsible for delays and the effects of time on outcomes of treatment, remedial actions may be suggested and emergency surgical care may be improved in Ethiopia.

\section{Methods}

\section{Study design and setting}

This prospective, 1-year, cross-sectional study was carried out at St Paul General Specialized Hospital in Addis Ababa, Ethiopia and Gondar University Hospital in Gondar, Ethiopia. The 2 hospitals where selected because the investigators practice in these 2 hospitals, each facility manages high volumes of emergency surgical cases, and we desired perspectives from 2 different settings. St Paul Specialized General Hospital is the second largest hospital in the country and Gondar University Hospital is the major referral hospital for northwestern Ethiopia.

\section{Patients}

We included all cases of surgically treated acute abdomen and all abdominal trauma cases admitted to the surgical wards of the 2 hospitals between 1 May 2008 and 30 April 2009. This included patients who underwent surgery after failure of conservative (nonsurgical) management and those who died without an operation. We excluded patients who were referred to other hospitals or who received nonsurgical treatment.

\section{Data collection}

Surgical residents and general practitioners working in the outpatient departments of the 2 institutions completed standardized data collection forms. Documented demographic information included age, marital status, income, and distance between residence or referring facility and the study site. The time interval-in days-from the onset of symptoms to initial presentation at the outpatient department of either study facility was recorded and was considered part of the prehospital interval. The time interval from first registration at the outpatient department to commencement of surgery-measured in hours and minutes-was regarded as the in-hospital preoperative interval. When inpatients absconded against medical advice but later returned to the hospital, the total time before the return was included in the prehospital interval.

\section{Data analysis}

Data were entered into Epi Info version 6 (Centers for Disease Control and Prevention, Atlanta, GA, USA) and was an- 
Table 4. Comparison of death by sociodemographic characteristics and pre-hospital time of Study subjects

\begin{tabular}{|c|c|c|c|c|}
\hline Characteristics & $\begin{array}{c}\text { Number of } \\
\text { studied cases }\end{array}$ & $\begin{array}{c}\text { Death } \\
(\%)\end{array}$ & $\begin{array}{c}\text { Crude } \\
\text { OR }(95 \%, \mathrm{CI})\end{array}$ & $\begin{array}{c}\text { Adjusted } \\
\text { OR }(95 \%, \mathrm{CI})\end{array}$ \\
\hline \multicolumn{5}{|c|}{ Age group (years; $n=504$ ) } \\
\hline$<25$ & 201 & 4.5 & $1.00^{*}$ & $1.00^{*}$ \\
\hline $25-44$ & 194 & 7.2 & $1.66(0.70,3.93)$ & $2.20(0.65,7.50)$ \\
\hline$\geq 45$ & 109 & 17.4 & $4.50(1.96,10.3)$ & $5.16(1.42,18.7)$ \\
\hline \multicolumn{5}{|l|}{$\operatorname{Sex}(n=504)$} \\
\hline Male & 367 & 7.1 & $1.00^{*}$ & $1.00^{*}$ \\
\hline Female & 137 & 11.7 & $1.73(0.90,3.34)$ & $2.10(0.80,5.46)$ \\
\hline \multicolumn{5}{|c|}{ Marital status $(n=489)$} \\
\hline Single & 238 & 3.8 & $1.00^{*}$ & $1.00^{*}$ \\
\hline Married & 230 & 11.7 & $3.38(1.55,7.36)$ & $1.97(0.37,10.3)$ \\
\hline $\begin{array}{l}\text { Divorced/ } \\
\text { widowed }\end{array}$ & 21 & 23.8 & $7.95(2.38,26.5)$ & $4.23(0.44,40.7)$ \\
\hline \multicolumn{5}{|l|}{ Education $(n=495)$} \\
\hline Illiterate & 75 & 1.3 & $0.08(0.01,0.60)$ & $0.001(0.00,+\infty)$ \\
\hline $1-6$ & 150 & 14.7 & $1.00^{*}$ & $1.00^{*}$ \\
\hline $7-12$ & 120 & 10.0 & $0.65(0.31,1.37)$ & $1.97(0.65,5.97)$ \\
\hline $12+$ & 150 & 4.0 & $0.24(0.09,0.62)$ & $0.37(0.06,2.08)$ \\
\hline \multicolumn{5}{|c|}{ Pre-hospital Time $(n=324)$} \\
\hline$<1$ day & 139 & 5.0 & $1.00^{*}$ & $1.00^{*}$ \\
\hline 2-3 days & 73 & 8.2 & $1.69(0.55,5.22)$ & $1.59(0.43,5.89)$ \\
\hline$>3$ days & 112 & 12.5 & $2.69(1.05,6.95)$ & $2.04(0.66,6.33)$ \\
\hline \multicolumn{5}{|c|}{ Hospital Time (n=393) } \\
\hline $0-3 \mathrm{hrs}$ & 291 & 7.2 & $1.00^{*}$ & $1.00^{*}$ \\
\hline$>3 \mathrm{hrs}$ & 102 & 5.9 & $0.80(0.31,2.05)$ & $0.95(0.33,2.73)$ \\
\hline
\end{tabular}

alyzed using SPSS version 13 (SPSS Inc., Chicago, IL, USA). Univariate and multivariate analyses were conducted. In the multivariate logistic regression analysis, the outcomes were death and postoperative complications, and the independent variables were sociodemographic characteristics and time delays. To adjust for confounding factors, dependent variables having marginal associations ( $P$ values below 0.2 ) with the independent variables were included. $P$ values $\leq 0.05$ were considered statistically significant.

\section{Ethical considerations}

Verbal informed consent was obtained from the patients seeking emergency surgical care. Ethical clearance and permission to conduct the study was obtained from the research and publication committees of both hospitals.

\section{Operational definitions}

Prehospital time: The time from the onset of symptoms to arrival at the referral hospital.

Complication at arrival: Unstable vital signs, shock, sepsis, or peritonitis upon arrival at the referral hospital.

\section{Hospital time}

Outpatient time: The length of time spent in the outpatient department.

Inpatient time: The time from leaving the outpatient department to the commencement of surgery.

Commencement of surgery: Onset of general anaesthesia. 


\begin{tabular}{|c|c|c|c|c|}
\hline Characteristics & $\begin{array}{c}\text { Number of } \\
\text { studied cases }\end{array}$ & $\begin{array}{c}\text { Complication } \\
\text { (\%) }\end{array}$ & $\begin{array}{c}\text { Crude } \\
\text { OR }(95 \%, C I)\end{array}$ & $\begin{array}{c}\text { Adjusted } \\
\text { OR }(95 \%, \mathrm{CI})\end{array}$ \\
\hline \multicolumn{5}{|c|}{ Age group (years; $n=504$ ) } \\
\hline$<25$ & 201 & 18.2 & $1.00^{*}$ & $1.00^{*}$ \\
\hline $25-44$ & 194 & 19.3 & $1.07(0.61,1.86)$ & $1.25(0.60,2.62)$ \\
\hline$\geq 45$ & 109 & 22.8 & $1.33(0.71,2.49)$ & $1.62(0.66,3.96)$ \\
\hline \multicolumn{5}{|l|}{$\operatorname{Sex}(n=504)$} \\
\hline Male & 367 & 17.9 & 1.00 & $1.00^{*}$ \\
\hline Female & 137 & 23.6 & $1.41(0.83,2.39)$ & $1.57(0.77,3.18)$ \\
\hline \multicolumn{5}{|c|}{ Marital status ( $n=489$ ) } \\
\hline Single & 238 & 17.5 & $1.00^{*}$ & $=====$ \\
\hline Married & 230 & 19.8 & $1.16(0.70,1.93)$ & $=====$ \\
\hline $\begin{array}{l}\text { Divorced/ } \\
\text { widowed }\end{array}$ & 21 & 29.4 & $1.96(0.65,5.93)$ & $=====$ \\
\hline \multicolumn{5}{|l|}{ Education ( $n=495$ ) } \\
\hline Illiterate & 75 & 16.4 & $0.92(0.42,2.03)$ & $=====$ \\
\hline $1-6$ & 150 & 17.6 & 1.00 & $=====$ \\
\hline $7-12$ & 120 & 23.7 & $1.46(0.76,2.79)$ & $=====$ \\
\hline $12+$ & 150 & 20.7 & $1.22(0.65,2.29)$ & $=====$ \\
\hline \multicolumn{5}{|c|}{ Pre-hospital Time (n=324) } \\
\hline$<1$ day & 139 & 10.5 & $1.00^{*}$ & $1.00^{*}$ \\
\hline 2-3 days & 73 & 16.7 & $1.70(0.69,4.20)$ & $1.90(0.76,4.77)$ \\
\hline$>3$ days & 112 & 25.8 & $2.96(1.39,6.30)$ & $2.67(1.23,5.80)$ \\
\hline \multicolumn{5}{|c|}{ Hospital Time (n=393) } \\
\hline $0-3 \mathrm{hrs}$ & 291 & 17.9 & $1.00^{*}$ & $=====$ \\
\hline$>3 \mathrm{hrs}$ & 102 & 19.3 & $1.09(0.59,2.03)$ & $=====$ \\
\hline
\end{tabular}

\section{Results}

A total of 504 cases of acute abdomen and abdominal trauma were analysed. Of these, 341 (69\%) were from St Paul Specialized General Hospital, and 163 (31\%) were from Gondar University Hospital. Seventy-five percent of patients were male, 50\% were married, and 68\% were between 15 and 44 years of age; the mean age was 32 years. Fifty percent had an annual income of less than US\$250 dollars, $84 \%$ were educated (elementary to college level), and $81.4 \%$ were Orthodox Christians. The sociodemographic characteristics of the study sample are summarized in Table 1.

At the onset of symptoms, $80 \%$ of study patients were advised by relatives or acquaintances to visit a healthcare facility. Sixty-six percent were referred to the study centres from other health institutions, of which $35.4 \%$ were hos- pitals. The time spent in the referring health facility varied from 10 minutes to 96 hours (mean $=12.6 \pm 22.1$ hours). The distance between the referring facility and the study hospital ranged from $1 \mathrm{~km}$ to $600 \mathrm{~km}$, (mean $=41.8 \mathrm{~km})$. Reasons for referral included expectation of better management (58.8\%) and inadequate resources at the referring facility $(22.5 \%)$. Ninety-one percent of the patients underwent imaging procedures at the referral hospital; $53.6 \%$ were $\mathrm{x}$-rays and $18.3 \%$ were ultrasound examinations. Haematological investigation was carried out for $83 \%$ of patients.

Trauma accounted for $11.6 \%$ of the cases, while the remaining $88.4 \%$ were nontraumatic acute abdominal conditions. These included acute appendicitis (44.4\%), intestinal obstruction (36.5\%), and perforated peptic ulcers (3.6\%). There rest of the cases (3.9\%) were classified as "other". The 
male-to-female ratios by diagnosis were: 5.3:1 for trauma, 2.2:1 for appendicitis, 2.7:1 for sigmoid volvulus, and 5.0:1 for perforated duodenal ulcers. Thirty-five percent of cases were complicated (according to the study definition) at the time of admission: $47 \%$ of these with peritonitis, $28 \%$ with shock, and $20.5 \%$ with sepsis. Twenty percent of the patients developed postoperative complications, including wound infection in $58.8 \%$ of these, wound dehiscence in $22.2 \%$, and pneumonia $22.2 \%$. Re-laparotomy was performed in $33 \%$. Forty-two cases (11\%) died after operation (Table 2).

The prehospital time was less than 1 day in $43 \%, 2$ to 3 days in $23 \%$, and more than 3 days in $35 \%$ of cases. Hospital time was less than 3 hours for $74 \%$ of cases and more than 3 hours for $26 \%$ (Table 3 ). Sixty-six percent of patients over the age of 45 years had a total prehospital time of more than 3 days; the adjusted odds ratio (OR) for this delay was 4.58 (95\% confidence interval $[\mathrm{CI}]=1.25$ to 16.8 ). In $60 \%$ of females, the prehospital time was longer than 3 days (adjusted $\mathrm{OR}=2.89 ; 95 \% \mathrm{CI}=1.31$ to 6.35 ). Fifty-four percent of the cases with a prehospital time of more than 3 days had initially visited other health facilities. Sixty-one percent of those with intestinal obstruction had prehospital intervals longer than 3 days (adjusted $\mathrm{OR}=1.65 ; 95 \% \mathrm{CI}=0.71$ to 3.83 ).

Cases with prehospital intervals exceeding 3 days had a case fatality rate of $67 \%$ (adjusted $\mathrm{OR}=3.71 ; 95 \% \mathrm{CI}=0.85$ to 16.2) (Table 4). Females and patients older than 45 years most frequently had prehospital intervals longer than 3 days (Table 5). There were more deaths among patients with intestinal obstruction than among those with acute appendicitis or perforated peptic ulcer disease.

\section{Discussion}

This 1-year study examined the effects of prehospital and in-hospital time on the outcomes of all acute abdmoen and abdominal trauma patients presenting to either study site during the study period. Acute appendicitis had the highest frequency, followed by intestinal obstruction and perforated peptic ulcer disease as causes of abdominal surgical emergencies. Intestinal obstruction had the highest mortality. These findings are consistent with earlier Ethiopian reports. ${ }^{10,12,14-16}$ There was no significant difference in the pattern of delay between the 2 referral hospitals. Marital status, education, income, and diagnosis were not associated with prolonged preoperative intervals, unlike age, gender, and referral from another health facility, which were significantly associated with delayed surgical intervention.

Delayed surgical treatment for acute abdomen and abdominal trauma significantly increased the risk of complications and death. Delay was associated with an inordinate number of patients presenting with complications at admission and postoperatively. We found that a delay of more than 3 days, which was the case for about $1.3 \%$ of patients, was associated with a significant increase in mortality.

The mean age of 32 was similar to that reported from a previous study on acute abdomen in Addis Ababa ${ }^{10}$ but disparate from a perforated peptic ulcer series from southern Ethiopia $(24.5 \pm 6.1$ years $) .{ }^{12}$ The latter report included chil- dren as young as 6 months old, unlike our study. Our study revealed significantly higher mortality and complication rates among patients older than 45 years; delays longer than 3 days were relatively common in this older age group. Other studies have shown delays in surgical care to be more problematic in older patients. ${ }^{12,13}$

Although trauma and acute abdomen are known to occur more frequently in males, ${ }^{1-4}$ in this study the ratios of men to women, stratified by disease type, were higher than expected. The male-to-female ratios for diagnoses of abdominal trauma, sigmoid volvulus, perforated peptic ulcer, and appendicitis in our study were all much higher than the recognized global ratios. These high male-to-female ratios were consistent with previous Ethiopian studies and substantiate the concern that Ethiopian women continue to lack access to surgical care. ${ }^{10,12}$ Women were also more likely than men to have prehospital and in-hospital intervals exceeding 3 days with unfavourable patient outcomes.

Our data showed that relatives and other nonprofessionals advised the patients to seek care at various health facilities. Many of the patients were then referred from health centres or smaller hospitals to the participating referral hospitals in Addis Ababa and Gondar. Primary health centre personnel normally would not be expected to perform abdominal surgery, and this study identified that many of the smaller hospitals did not have the capacity to treat common abdominal surgical emergencies. Of particular concern was that patients who first attended health centres or smaller hospitals were more likely to be delayed than those who went directly to either of the referral hospitals. Patients who went directly to the referral hospitals were less likely to suffer complications or death than those who were referred from lower-level hospitals or health centres. These finding indicate that there are important health system factors that contribute to delays in surgical care for abdominal emergencies.

Most of the patients were underwent prompt surgery at the 2 referral hospitals and did not experience serious adverse outcomes resulting from delays within the referral hospitals. There were no adverse effects specifically associated with in-hospital delays at the referral institutions; this was perhaps because the effects of prehospital delays so greatly outweighed those of the in-hospital delays that the effects of in-hospital delays were obscured.

Other studies have shown that delays of more than 3 days for acute abdomen or abdominal trauma patients adversely affects outcomes. ${ }^{6,7,9}$ Our study has supported this, with increased morbidity and mortality noted in patients with delays longer than 3 days. Prehospital time was the major contributor to these dealys. Prehospital delays, which were associated with adverse outcomes, were associated with both patient and healthcare system factors. Patient factors included female gender and age above 45 years. The neglect of older people and women could be related to lack of community knowledge and lack of female and elderly empowerment. To reduce delays among these patients and thus improve their outcomes, we recommend education to increase public awareness of the symptoms and risks of surgical abdominal 
emergencies among women as well as middle-aged and elderly patients.

This study had several limitations. The prehospital interval was reported in days. More precision in this measurement might have shown that delays shorter than 3 days were also important. Moreover, missing data affected our results; this was partly due to the unwillingness of some respondents to provide sensitive information, such as income. This study was conducted only in public institutions; evaluation of the management provided in the private system would also contribute to an understanding of surgical care of abdominal emergencies in Ethiopia.

\section{Conclusions}

Delays of 3 days or more adversely affected outcomes among acute abdomen and abdominal trauma at the 2 study sites. Women, patients older than 45 years, patients with intestinal obstruction, and those who were referred from lower-level health facilities were delayed more frequently and had more adverse outcomes. Future research should investigate the reasons for delays, particularly among women and patients older than 45 years of age. Education programmes on surgical referrals by nurses, health officers, and general practitioners are required and resources should mobilized to assure adequate surgical training for these professionals. Future investigations of prehospital delays of acute abdomen and abdominal trauma surgery should specifically evaluate delays in appropriate referral and the availability of safe transport. For a better understanding of the management and outcomes of abdominal surgical emergencies in Ethiopia, we also recommend investigations of private sector surgical care and research into the reasons that small hospitals do not provide surgical care.

\section{Acknowledgements}

We would like to thank the Canadian Network for International Surgery (CNIS) and the Canadian International Development Agency (CIDA; now Global Affairs Canada) for funding this study. We also thank all staff involved in the care of these patients.

\section{Competing interests}

All authors declare that they have no competing interests related to this work.

\section{References}

1. Søreide $K$, Krüger $A J$, Vårdal $A L$, Ellingsen $\mathrm{CL}$, Søreide E, Lossius HM. Epidemiology and contemporary patterns of trauma deaths: changing place, similar pace, older face. World J Surg. 2007 Nov;31(11):2092103. doi: 10.1007/s00268-007-9226-9.

2. Lal SK, Morgenstern R, Vinjirayer EP, Matin A. Sigmoid volvulus an update. Gastrointest Endosc Clin N Am. 2006 Jan;16(1):175-87. doi: 10.1016/j. giec.2006.01.010.

3. Svanes C, Salvesen $H$, Stangeland L, Svanes K, Søreide O. Perforated peptic ulcer over 56 years. Time trends in patients and disease characteristics. Gut. 1993 Dec;34(12):1666-71. doi: 10.1136/ gut.34.12.1666.

4. Shepherd JA. Management of acute abdomen. New York: Oxford University Press; 1982.

5. Flook DJ, Crumplin MK. The efficiency of management of emergency surgery in a district general hospital--a prospective study. Ann R Coll Surg Engl. 1990 Jan;72(1):27-31.

6. Henderson KI, Coats TJ, Hassan TB, Brohi K. Audit of time to emergency trauma laparotomy. Br J Surg. $2000 \mathrm{Apr} ; 87(4): 472-$ 6. doi: 10.1046/j.1365-2168.2000.01392.x.
7. Clarke JR, Trooskin SZ, Doshi PJ, Greenwald $\mathrm{L}$, Mode CJ. Time to laparotomy for intraabdominal bleeding from trauma does affect survival for delays up to 90 minutes. J Trauma. 2002 Mar;52(3):420-5.

8. Chung $\mathrm{CH}, \mathrm{Ng} \mathrm{CP}$, Lai KK. Delays by patients, emergency physicians, and surgeons in the management of acute appendicitis: retrospective study. Hong Kong Med J. 2000 Sep;6(3):254-9.

9. Von Titte SN, McCabe CJ, Ottinger LW Delayed appendectomy for appendicitis: causes and consequences. Am J Emerg Med. 1996 Nov;14(7):620-2. doi: 10.1016/ S0735-6757(96)90074-1.

10. Asefa Z. Pattern of acute abdomen in Yirgalem Hospital, southern Ethiopia. Ethiop Med J. 2000 Oct;38(4):227-35.

11. Tegegne A. Management of small intestinal volvulus in a district hospital. Trop Doct. 1995;25 Suppl 1:54-7.

12. Ersumo T, W/Meskel $Y$, Kotisso B Perforated peptic ulcer in Tikur Anbessa Hospital: a review of 74 cases. Ethiop Med J. 2005 Jan;43(1):9-13.
13. Meara JG, Leather AJ, Hagander L, Alkire BC, Alonso N, Ameh EA, et al. Global Surgery 2030: evidence and solutions for achieving health, welfare, and economic development. Lancet. 2015 Aug 8;386(9993):569-624. doi: 10.1016/S01406736(15)60160-X. Epub 2015 Apr 26.

14. Ersumo T, Ali A, Kotisso B. Complicated peptic ulcer Disease in Tikur Anbessa Hospital, Addis Ababa. Ethiop Med J. 2004 Apr;42(2):87-95.

15. Ali MK. Treatment of sigmoid volvulus: experience in Gondar, north-west Ethiopia. Ethiop Med J. 1998 Jan;36(1):4752.

16. Franz MG, Norman J, Fabri PJ. Increased morbidity of appendicitis with advancing age. Am Surg. 1995 Jan;61(1):40-4. 